\title{
Does the Engineering Culture in UK Higher Education Advance Women's Careers?
}

Does the Engineering

Culture in UK Higher Education Advance Women's Careers?

by A. Powell, B. Bagilhole, A. Dainty and R. Neale, Dept. of Social Sciences, Loughborough University, Loughborough, Leicestershire, LE11 3TU, UK. Email: A.Powell@lboro.ac.uk

\begin{abstract}
Current research suggests that increases in the number of women studying engineering and related courses have not been matched by a similar increase in women engineering professionals. This suggests that although women are attracted to engineering, their experiences in higher education (HE) discourage them from pursuing their chosen career path. The paper explores whether the masculine culture of the engineering sector permeates the culture and curriculum in engineering HE, and if it does, what impact this has on women engineering students. This is achieved through semi-structured, qualitative interviews with a range of female engineering students from both the pre and post 1992 university sectors. Findings indicate that while women are not deterred from pursuing their chosen engineering career, the culture and structure of the engineering education system has been designed for a male audience. This suggests that engineering HE does not benefit most female students to the same extent as male students. It is recommended that HE engineering must review its structure, culture, practices and curriculum if it is to retain female engineering graduates and to attract more women into the sector. This paper fulfils an identified gap in research on women in engineering and will be of interest to university engineering departments and faculties and the Engineering Council, as well as to those in the fields of social policy, education and equal opportunities.
\end{abstract}

Keywords: Engineering, culture, women, higher education, career

\section{Introduction}

Engineering is quantitatively and hierarchically male-dominated. This is highly significant given the impact of engineering on society. Engineering has a popular image of being tough, heavy and dirty. These powerful cultural images have helped to reproduce occupational segregation whereby engineering has been perceived as unsuitable for women. In response to skills shortages in technological expertise, a number of UK government initiatives have been introduced to encourage women to pursue engineering degree courses. While such programmes have had some success in increasing the proportion of women studying engineering, there has not been a proportionate increase in the number of women engineering professionals. This indicates that although women are attracted to engineering, their experience 
Does the Engineering

Culture in UK Higher Education Advance Women's Careers? of engineering in HE discourages them from pursuing their chosen career path. This may be because women's expectations of engineering are unmet at university. This paper therefore explores whether the masculine culture of the engineering sector permeates the culture and curriculum in engineering HE. Moreover, it examines whether HE experiences advance women's careers, or whether they deter them from pursuing their chosen career in the engineering professions.

\section{Women In Engineering}

Nancy Lane, co-author of 'The Rising Tide' report on women in science, engineering and technology, has commented that, 'Engineering ... is a subject where women are currently catastrophically underrepresented' (1997, p. 41). That women remain a minority in engineering has been explained in various ways, including poor or inadequate guidance counselling prior to entering university; early differential socialisation of males and females; lack of support from family, friends and professional engineers; and cultural and occupational barriers (Dryburgh, 1999). Sagebiel (2003), for example argues that various studies have shown that what drives women away from technology are not women's deficits in abstract thinking, but the content and climate prevalent in academia, which construct an atmosphere of dominant masculinity.

Recently a business case has been argued for the increase of women in the engineering sector. Bagilhole (1997) has argued that this essentially rests on two premises: that the industry is under-utilising the full range of skills and talents in the population because of continuing unequal opportunities for some groups in society; and that it should be possible for organisations to increase their efficiency and effectiveness by projecting a more pluralistic self-image, thereby widening their pool of potential customers. This argument has resulted in several UK government initiatives aimed at encouraging women to pursue engineering careers. These initiatives have had some success in increasing the proportion of women studying engineering. Glover (2000) for example, showed that in 1973 only 3\% of engineering and technology graduates were female. This is compared to $15 \%$ in $2001 / 02$ (HESA, 2002), although figures vary widely by discipline. However, there has not been an equivalent increase in women engineering professionals. Kirkup and Keller (1992) found that only about half of women students go on to work as engineers, while Fielding and Glover (1997) suggest that even optimistic estimates maintain less than $10 \%$ of professional engineers are women. This therefore raises the question of whether something happens to women in engineering HE to deter them from pursuing their chosen career path.

\section{Engineering Culture}

The central role of engineering in society and the economy is not necessarily evident to the public at large or to the media in particular. The engineering profession is considered by many to be a somewhat dull, uncreative activity, 
associated with the so-called 'old-economy' (Malpas, 2000). Historically the image of engineering has been tough, heavy, dirty and to do with machinery. In terms of cultural image, engineering is perceived as a masculine profession. This is not only because the workforce is male, but also because the prevailing culture and ethos of engineering appears to be extremely male (Gale, 1994). These cultural images have remained powerful and have helped to reproduce the perception that engineering is unsuitable for women (Evetts, 1998). This represents a somewhat self-fulfilling cycle, reinforcing the masculinity of the industry. It has been argued that this is a result of the polarised characteristics supposedly attached to gender in the process of socialisation. Sagebiel (2003) states that engineering can be considered gendered in three ways. Firstly, gendered structures are visible in gender difference in the division of labour and in the work styles of women and men. Secondly, the symbols and images of engineering knowledge and practice are gendered through cultural associations between masculinity and technology. And thirdly, individual engineers have gendered personal and professional identities and experiences.

There is empirical evidence to suggest that women suffer if they go against such cultural dictates (Evetts, 1998). This is supported by Glover $e t$ al (1996) who indicate that women actively choose not to enter science, engineering and technology (SET) careers in the knowledge that they are likely to feel discomfort. This is because when women undertake 'male work', they upset a widely accepted sense of order and meaning (Cockburn, 1985). Although women can cope with the actual engineering work, they are likely to find it much more difficult to cope with the engineering culture (Evetts, 1998). Some women therefore pay both personal and social costs when they cross the threshold into a male domain (Bagilhole, 2002). Opportunity 2000 (1996) suggests that this is because young women in science and engineering, for example, find themselves working with the values, systems and performance criteria which have been set up by men for men, and not for women.

By contrast, Bennett et al (1999) claim that women who seek a career in the construction industry are socialised into its culture through the education system and appear actively to seek that culture. Gale (1994) described gender values as a continuum ranging from male to female and suggests that women holding similar values are attracted to similar occupations. Bennett et al (1999) do, however, concede that the reverse is also true: many women reject the construction culture, as do many men.

\section{Engineering HE Culture}

This paper aims to question whether the culture in engineering education mirrors that in the workplace? Mills and Ayre (2003) suggest that there have been a number of findings that many women experience a 'chilly climate' in SET courses, and it is likely that other minority groups share similar experiences. Unhappy or uncomfortable students will not achieve as well as they
Does the Engineering

Culture in UK

Higher Education

Advance Women's

Careers?

.


Does the Engineering

Culture in UK

Higher Education

Advance Women's

Careers? might in a more supportive environment, and they may even leave the course. Some of the features of the 'chilly climate' that Mills and Ayre (2003) identified are:

- $\quad$ Erroneous assumptions by lecturers that all students have prior 'tinkering' experience (practical familiarity with mechanical and electrical devices and appliances) (Lewis, 1995)

Lack of excitement in the content or presentation of the course (Nair and Majetich, 1995)

- $\quad$ Apparent lack of relevance in the curriculum content (Lewis, 1995; Lintern, 1995)

- $\quad$ Teaching methods that are appropriate for only a very limited range of learning styles (Lewis, 1995; Jolly, 1996)

- $\quad$ Disruptive behaviour of majority groups (e.g. white male students throwing paper planes) (Lintern 1995; Jolly 1996), and

- $\quad$ Classroom atmosphere uncomfortable for some students because of racism, sexism, or similar attitudes (Lewis, 1995; Lintern 1995; Jolly 1996; McLean et al, 1997).

On the other hand, McIllwee and Robinson (1992) argue that engineering HE culture values academic work at which women excel, whereas engineering workplace cultures value such masculine strengths as "a fascination with technology, expertise as a tinkerer, and an aggressive style of self-presentation" (p.50). They argue that knowing how to conform to the masculine engineering culture and doing it well are critical to women's success in the workplace. However, they only consider that this becomes an issue when women make the transition from education to work. They believe that in the workplace women engineers not only have to show competency in their knowledge and skills but also have to learn to perform and enact masculine norms of attitude and interaction. While, this is not disputed, McIllwee and Robinson fail to recognise that the very knowledge and skills women learn in engineering education, or at least the ways in which these skills are taught and learnt, encompass masculine norms and attitudes.

The US National Council for Research on Women report (Thorn, 2000) has shown the importance of the first year for women having entered engineering in HE. Since women tend to evolve an interest in technology over time, the typical first year 'killer' exams designed to weed out students rather than invite their participation may be counter productive for retaining female students. Copeland (1995), however, indicates that "recognising the different skills, perspectives and learning styles that women bring to engineering and incorporating these into the teaching and learning environment" means challenging the assumptions and practices within engineering itself. 
Part of the problem may be that once the decision to study engineering has been made, commitment to the field does not automatically follow. Etzkowitz et al. $(2000,133)$ show that educational experiences have a cascade effect on commitment: "A cascade of affirming experiences serve to amplify a string of positive effects, until there is a short-circuit and the process is reversed ... what had the potential for a cumulative positive cascade of experience becomes short-circuited by negative experiences"

\section{Engineering HE Structure}

Lewis (1995) found engineering teaching to be strongly male biased: "The research questions, methods, criteria of success, and styles of teaching are male defined, and consequently, the knowledge itself reflects a bias towards a male cognitive style in its practices, theories, and ways of teaching”. This is a worrying trend given that Mills and Ayre (2003) emphasise the desirability of structuring an engineering curriculum around a general recognition that students from diverse backgrounds bring different perspectives, attitudes and values to the engineering classroom, without making distinctions between the specific cultural groups represented in the class. This is supported by Sagebiel (2003), who suggested that an improved curriculum would make both the climate and content of teaching appropriate to attract and retain both men and women. Improved teaching is particularly relevant to women, as the WEPAN (Women in Engineering: Programmes and Advocates Network) policy climate survey, exploring the environment for undergraduate engineering students, found that men are less affected by poor teaching, poor organisation of course material and by dull course content (see Sagebiel, 2003).

In addition to direct sexism and the numerical domination of men studying, teaching and practising science, gender stereotypes have been reinforced by taking boys' experiences as the norm while marginalizing those of girls (Srivastava, 1996). Kelly (1985) explains that this has occurred through the representation of gender in textbooks, the male orientated curriculum (such as in examples and applications used) and classroom interaction. In the presentation of science education, women scientists have been invisible (in terms of numbers and examples given). Science is presented out of context, without reference to local or social issues and implications. Moxham and Roberts (1995) describe this as a gender-exclusive curriculum, with bias in language, assumptions, curriculum design, classroom interactions, and teaching and assessment methods. This problem is significant as girls are seen to be 'best' at contextualised, purposive, relational learning, appreciating complexities rather than reductionism (Jorg and Wubbles, 1987).

Thomas (1990) showed that disillusionment amongst students has arisen through excessive maths and quantitative content, narrowness and the abstraction of the curriculum, lack of relevance to the 'outside' world, too early specialisation and the need to conform to rigid rules, without the
Does the Engineering Culture in UK Higher Education Advance Women's Careers? 
Does the Engineering

Culture in UK Higher Education Advance Women's Careers? opportunity to challenge them. This has led to passive learning, acceptance of facts on trust and frustration. In terms of the learning context and curriculum, both Greed (1991) and Thomas (1990) describe the impersonal and indifferent atmosphere of science and technology departments. This is manifested, for example, in formal teaching methods and the interpretation of professionalism in masculine terms. As Byrne (1990) points out, teaching styles in science and technology are instrumental and non-negotiable. As a result of these methods of teaching there is little debate, interaction or concern for the aesthetic.

Madhill et al. (2003) write that career decision-making is impacted on by a number of factors, of which hands-on experience is particularly influential. Without the opportunity for hands-on learning, students report that they do not automatically appreciate the application of what they are studying to their personal aspirations and the things they care about. Many students in Srivastava's (1996) study also pointed to the lack of opportunity for practical work. They felt the emphasis on broad, theoretical, historical and textbook contexts was irrelevant, limited in usefulness and remote from industry.

\section{Curriculum Content}

Mills and Ayre (2003) suggest that the typical engineering curriculum has been blamed for the difficulties in recruiting and retaining female engineering students. Beder (1989) describes it as showing an "obsession with the technical, the mathematical, and the scientific, and an almost complete neglect of the social, political and environmental issues" which discourages "students with broader interests, a different range of talents ...; those who want to work with people rather than machines and numbers, those who care about social relations. Too often it is the female students who are put off" (Beder, 1989, p173). Thomas (1990) also suggests that HE curriculum is male-centred. She shows that subjects are not neutral but gendered in that they are socially and culturally constructed. Weiss et al (1990) argue that teaching and assessment material familiar and relevant to women, including the ethical, human and social context of science and technology, should be incorporated into the curriculum. Hodgson (1993) illustrates the appeal of interdisciplinary courses, for example the use of social science, health, environmental and philosophical concepts, processes and problems in science and technology courses.

Srivastava's (1996) research showed that construction tutors and some professional body representatives defined construction and construction practices in technical terms and therefore, emphasised core knowledge as maths, science and technology. Many female construction students found this focus difficult, irrelevant, disappointing and uninteresting. There was some recognition of the need for a more balanced, broad curriculum, especially the inclusion of management, which female construction engineering students enjoyed. However, change was limited because tutors, the majority 
of students and professional body representatives supported the primacy of the technical definition of construction problems. Srivastava (1996) recommended a need for radical change in construction $\mathrm{HE}$, and her recommendations are equally applicable throughout the engineering disciplines. She maintains that such changes may involve presenting construction disciplines in a social context; considering practical applications; integrating modules from social sciences and humanities; questioning assumptions, traditions and the culture of construction education and practice; relating topics to a range of student experiences; addressing the social and environmental impact and benefits of construction; incorporating interactive, qualitative, critical and ethical considerations in projects; and mentoring of students and staff who are in a minority. Language and examples used in construction course content are important conveyors of culture and values and should not be exclusionary, sexist, ethnocentric or homophobic. She also suggested that feminist perceptions of science and technology should be incorporated into the construction curriculum, to facilitate questioning of assumptions, and challenge conservatism and traditionalism in the construction curriculum industry. There should be further easing of professional bodies' influence on construction course design and content and more autonomy given to construction tutors to make space in the curriculum for new and more relevant areas, and also for independent study, reflection, discussion and debate.

\section{Methodology}

The research presented in this paper is based on part of a larger Economic and Social Research Council funded, longitudinal research project investigating the influence of women engineers' earliest encounters with engineering workplaces on their future career intentions. The focus in this paper is on women's experiences of engineering $\mathrm{HE}$, and specifically analyses whether the engineering culture hinders or facilitates women's careers in the engineering sector. The study explores the experiences of female students from a range of engineering disciplines, including construction/civil, aeronautical, mechanical, design and technology, and other degree courses. The research therefore recognises that engineering is not a single, homogeneous sector, as it has often been treated in previous research (Evetts, 1996).

A qualitative methodological approach was used in order to explore the experiences and reflections of women engineering students and the everyday practices and interactions in the engineering classroom. In-depth, semi-structured interviews took place with forty-six second year female students from a range of engineering disciplines and courses at a pre and post 1992 university. The use of a semi-structured interview schedule meant that key issues identified by the researchers could be explored, while at the same time interviewees could define issues according to their own experiences and understandings. All of the data collected were tape-recorded and transcribed verbatim, before being analysed in NVivo. NVivo allowed the conceptual labelling and analysis of the data through a series of networks of
Does the Engineering

Culture in UK

Higher Education

Advance Women's

Careers?

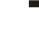


Does the Engineering

Culture in UK Higher Education Advance Women's Careers? nodes and links. This tool helped develop a comprehensive insight into the students' experiences of culture in the engineering classroom.

\section{Findings}

The analysis of interview findings revealed two principal themes relating to women's experience of culture in engineering HE; teaching and learning methods and classroom interaction. The findings under each theme are elaborated below, but it is important to note that they are not exclusive but intertwined and mutually reinforcing.

\section{Teaching and Learning Methods}

This theme refers to the ways in which engineering is taught to, and learnt by, students. It can therefore be broken down into the following subsections: curriculum content; practice versus theory; volume of work; and assessment methods.

\section{Curriculum Content}

As was suggested in the literature, students were found to be attracted to a curriculum that offered more than technical engineering:

"When I tried to get into my course it was ... the commercial management that attracted me. I think that if I don't do well in the engineering sector, I [can] do the commercial bit"

BSc Commercial Management \& Quantity Surveying Student

This quote, however, also highlights women's lack of confidence in their ability at technically oriented subjects, and that women may not have decided if they definitely want to pursue a career in their chosen degree course. Indeed, many other courses did not offer students the opportunity to choose their own modules:

"Some of the work we do, you're like why? Why do I need to know this? Or, why are we learning it now? I think we could have spent more time on other stuff"

\section{MEng Civil Engineering Student}

"Sometimes ... you think what the hell is going on here? When you're doing this crazy maths you think 'what does this apply to?' But you've just got to ask, 'what's this in real life?' and then they'll tell you"

\section{MEng Aeronautical Engineering Student}

The problem here is that students need the confidence to speak up and ask questions in class, and as we have seen girls often lack confidence in male-dominated environments. One solution to issues of relevance would be to introduce more optional modules, however the difficulty in introducing more choice is highlighted by one student: 
"The thing is if the ICE [Institute of Civil Engineers] say you've got to do this stuff you've got to do it because they're the guys that affiliate our course"

MEng Civil Engineering Student

\section{Practice Vs. Theory}

Another aspect of learning methods is whether students learn through theory or practical application. Most students recognised that theory was an essential part of the learning process, but they also thought practical, hands-on work could play a greater role in the course:

"I expected it to be a bit more practical. The theory isn't too bad, but there's so much to take in and to understand. I'd personally like a bit more practical."

\section{BEng Mechanical Engineering Student}

Conversely, students who had experienced very practical modules such as surveying "where you actually go out and learn how to use the instruments" (MEng Civil Engineering Student), thought that what they had learnt would be invaluable, particularly when they moved into industry. This suggests that some women engineering students were looking to immediately utilise vocational knowledge from their degree programmes that they could arguably acquire fairly rapidly upon embarking on their professional careers.

\section{Assessment Methods}

The majority of students interviewed preferred coursework to exams, even though coursework usually accounted for a very small proportion of assessments:

I think that the people that are more practical are probably the people who don't do so well in exams. They are so theoretical ... This semester we've only had like 20\% [coursework] for each module. So that's $80 \%$ exams. So if you do crap in the exams then it really buggers you up. I did ok on the coursework, I got like A's and B's, and I wish they'd been worth more really. I do enjoy the $100 \%$ coursework modules, because we had one last year. It was engineering design, it was group work but it was so good. We had to design this building and we did everything for it ... it was really fun."

\section{MEng Civil Engineering Student}

This quote also highlights a close relationship between the dichotomies of practical and theory work, and coursework and examinations. However, not all students favoured coursework:

"The amount of coursework that we get is phenomenal ... it's like we've got to hand in six pieces of coursework and an exam in two days."

BA/BSc Industrial Design and Technology Student 


\section{Volume of Work}

Does the Engineering

Culture in UK

Higher Education

Advance Women's

Careers?
Although many students mentioned quantity of work, it was mainly Industrial Design and Technology Students that referred to the volume of work they had:

"It's been a lot more hours than I thought it'd be, it's like 24-7, just working. I've got lectures most of the day, and then I'm working at night to do the stuff that they've set us in our lectures"

BA/BSc Industrial Design and Technology Student

"The worst things are the amount of work ... we have a lot of deadlines in at the same time. You don't get much sleep at all. A lot of the work is very time consuming ... there's always an on-going project. But then, I suppose that's something I like anyway"

BA/BSc Industrial Design and Technology Student

There remained a perception amongst many female engineering students that they worked harder than those in the social sciences, arts and humanities areas. Although data was not collected to explore the validity of this perception, some alluded to the additional efforts necessary to succeed in group work, which dominated coursework assessment within the engineering faculty.

\section{Classroom Interaction}

This theme relates more specifically to the relationships between staff and students. Issues such as stereotyping, discrimination and banter are revealed within this theme, although teaching and learning methods are often the mechanisms they are played out through.

\section{Student Relationships}

Many of the students referred to bonding with their fellow course mates, and seemed to draw attention to this because it distinguished them from students on other courses, particularly in the social sciences and humanities:

“All my course mates, they're really friendly and helpful, not like some other courses. Some other courses they don't know who are on the course and they don't communicate."

BEng Chemical Engineering Student

"The best thing is the people you meet. They're all kind of like minded ... because it's such a difficult degree everybody helps each other, like when we've got a really tough piece of coursework ... the people who've done it will come over and help the people who haven't. It's a really nice spirit amongst everyone."

BEng Aeronautical Engineering Student

In contrast, some students did suggest that male students could be patronising and undermining toward female students: 
"If you've done something wrong - if it's a lad they'd get scorned for it, whereas if it's a girl, you get 'oh, she's only a girl, what's she supposed to know about it? She's not as good as everybody else' ... you're having to prove yourself continuously."

MEng Mechanical Engineering Student

Students on the engineering courses are also described as competitive:

"The course is a lot more competitive than I expected it to be ... there are really, really nasty people who do not want you to succeed."

BA/BSc Industrial Design and Technology Student

"It's quite competitive on the course. People know where people are in [comparison] to themselves so you don't want to fall behind."

MEng Civil Engineering Student

Many students suggested that communication between their peers, in relation to work (for example in group work), tended to be poor:

"Trying to get the boys to listen to anything you're saying is difficult ... the boys just wouldn't listen to a word that Rachel was saying ... I had to persuade them to listen to what she was saying, and I found that really frustrating that they just wouldn't listen"

\section{MEng Mechanical Engineering Student}

"Communication was non-existent and I was left out in one way or another. They wouldn't tell me there was a group meeting ... It was peer assessed ... they marked me right down, which I felt was completely unfair because within the boundaries they'd placed on me, I'd done the best I could."

best I could."
Does the Engineering

Culture in UK

Higher Education

Advance Women's

Careers?

$$
\text { MEng Civil Engineering Student }
$$

This finding supports the assertion stated earlier that women engineering students work harder by virtue of the emphasis on group assessed coursework.

\section{Student-Staff Relationships}

On the whole, the students had a seemingly positive attitude towards their lecturers. They found them motivating and supportive, and a number of students viewed some of their male and female lecturers as role models and mentors. However, a number of students highlighted gender issues when they spoke about their lecturers, such as staff making sexist banter (although this was usually discussed as 'only' joking):

"Now and then [male lecturers] make ... female jokes but I wouldn't say they necessarily treat you differently on purpose"

BA/BSc Industrial Design and Technology Student 


\section{Does the Engineering \\ Culture in UK \\ Higher Education \\ Advance Women's \\ Careers?}

"Even getting here because we didn't have Physics [A level], we both found that it was 'Girls, we do anything we can to get girls on the course'. But otherwise, we don't have a problem at all."

BEng Automotive Engineering Student

One student indicated that male lecturers might not be comfortable with female students:

"Some of [the male lecturers], they're quite happy to sit and chat to the guys, but they don't really know what to say [to the female students] ... it's almost as if you're not somebody who's normal."

MEng Civil Engineering Student

Several students also felt they were put in an awkward position when staff appeared to offer them more help than male students because they were female:

"It's nice [tutors] go all out to help you, but it can feel sometimes that it's because you're a girl that they go all out to help you and it can be a little bit sleazy. One guy ... he's just really unbelievable. He'll take you from the back of the queue, bring you right in front of all these lads and help you - pretty much do it for you, which you're not going to complain if someone's offering to help, but then you get grief off the lads ... they put you at a disadvantage."

BA/BSc Industrial Design and Technology Student

As indicated earlier, however, it may be that lecturers legitimately offer female students more help because they appear less confident with their work than male students:

"I think some of the male lecturers are more helpful to the girls than to the guys ... but then I think it might be because the girls come across as less confident that the teachers want to help them more."

BA/BSc Industrial Design and Technology Student

Alternatively, lecturers may help female students more because some women are able to manipulate male members of staff, or rather, use their gender to their own advantage, as this student indicates:

"[Male lecturers] feel like they have to look after you more but generally because that's the way I play it with them, because then you get what you want more."

BEng Materials with Management Studies Student

This attitude was not, however, favoured by all students:

"Most of [the lecturers] will [treat you differently] up to a point. I mean if you blatantly push the fact that you're a girl, they will treat you differently."

BEng Mechanical Engineering Student 
This quote indicates that some students believe it is necessary to act like 'one of the lads', and play down their gender, in order to be accepted in engineering.

In addition, one student felt singled-out because of her gender when a lecturer complained to her personal tutor that she had missed a lecture. The Architectural Engineering and Design Management student felt victimized because the lecturer failed to notice if male students were absent from class. Another student felt that when she complained that the male students she was working with were treating her unfairly, her female personal tutor failed to take her seriously:

"I told [my personal tutor] there were boys who were harassing me ... they'd end up giving me the work ... I told her about it and she was like, 'well, it'll pass' ... she didn't even call them to talk to them."

BSc Commercial Management and Quantity Surveying Student

\section{Discussion}

While these findings do not show that the culture and structure of engineering HE actively deters women from pursuing careers in their chosen profession, they clearly indicate that the practices discussed in the literature do exist, and that the male engineering culture generally does indeed permeate engineering education.

Teaching and learning methods are part of the structure of engineering HE that Lewis (1995) described as 'strongly male biased'. While students' opinions in the research may not have been as strong as those expressed in the literature (Moxham and Roberts, 1995; Thomas, 1990; Srivastava, 1996), it is evident that the female students' did not always approve, or feel comfortable with, curriculum content, assessment methods, the volume of work they had, or the emphasis on theory as work. However, given the perceptions of engineering in society at large as 'dull and uncreative' (Malpas, 2000), it may be considered an anomaly that the teaching and learning methods on engineering courses did not meet the women students' expectations. It is likely, therefore, that given the women's interest in engineering, they had a much more positive view of engineering than the public generally. Alternatively, women who accept male-centred teaching and learning methods may, as Bennett et al (1999) have suggested, actively seek the engineering culture. To state that the teaching and learning practices on engineering course are male biased infers a homogeneity that is no truer of men than it is of women - there are as many differences between men and between women as there are between men and women.

Possible solutions to the male-centred teaching and learning methods in engineering and related courses involve, among other things, introducing greater choice for students, such as the option to choose management or social science modules, or 'softer' engineering modules that address the social and environmental impact of engineering, as suggested by Srivastava (1996). The difficulties with this are that core modules may have to be

\section{Does the Engineering Culture in UK Higher Education Advance Women's Careers?}


Does the Engineering

Culture in UK Higher Education Advance Women's Careers? dropped to make way for change; the volume of work the students had was considered overwhelming, so to introduce additional modules would be unrealistic. However, on many courses the modules and topics covered are dictated by the professional bodies that accredit courses (students also need to cover certain areas if they want to get Chartered Engineer status), which are unlikely to favour the introduction of optional modules. The ethos, and rigidity of the system, in engineering therefore intimates that if individuals want to achieve in the sector they must conform to existing masculine norms and attitudes (Mclllwee and Robinson, 1992).

The findings relating to classroom interaction and the relationships between students and between staff and students show that the engineering culture is mirrored in the engineering classroom. While most students felt they were treated fairly and justly, the women did encounter sexist banter and often felt undermined by their male peers and staff. However, students often dismissed sexist 'jokes'. This may be as a result of women attempting to 'fit in' or being loyal to the majority group by allowing themselves to provide a source of humour for the class (Kanter, 1977). An alternative explanation may be that, as noted above, women who have chosen to pursue a career in engineering have positive perceptions of the industry; they are unlikely to have chosen this course otherwise. Therefore at the early stages of their career sexist 'jokes' are interpreted as just that, jokes. It is only after years of consistent 'joking' that, for some women, what Etzkowitz et al (2000) call the 'short-circuit' effect occurs, and women become disillusioned with their chosen career. While such banter and stereotyping may be accepted early in women's engineering careers, its future impact should not be underestimated. Future research may therefore ask women who have spent some time in industry about their educational experiences. These women will not only be able to reflect on the impact these experiences have had on their future career, but hindsight may also mean they are better able to reflect objectively on their experiences.

A further aspect of classroom interaction is the competition and poor communication among students. This is an inherent part of the engineering culture, and while learning techniques (such as those suggested by Srivastava, 1996) can be introduced to combat this, some will not always work. Group work in education, for example, does not always lead to collaboration and the development of team skills (as in industry) because the university structure is individualistic; students achieve, and are awarded degrees, on the basis of individual merit.

The research also shows how women assimilate into the engineering industry by attempting to become 'one of the boys'. This is evident in students and staff alike, as shown by the student who felt that some women flaunted their gender too much. Comments such as this emphasise how femininity and engineering are perceived as incompatible. This situation and the one where a female lecturer ignored a student's harassment problems do little to further women's cause in engineering. If such women succeed in engi- 
neering, they do so as individuals, failing to question the status quo. Their career success is unlikely to promote the interests of women in the sector (Greed, 2000). It is therefore essential to change the culture in the engineering classroom and culture.

While changing the structure of engineering education (such as teaching and learning practices) is fraught with difficulties, it is at least possible to recommend some solutions. This said, it is almost impossible to implement structural change without the support of key actors, such as the professional bodies, engineering faculties, and lecturers. It is therefore paramount that the traditional male attitudes and culture that still dominate the engineering professions and education are transformed. Achieving cultural change is, however, a difficult task that is likely to take many years to accomplish.

\section{Conclusions}

This paper has explored whether the masculine culture of the engineering sector permeates engineering in $\mathrm{HE}$, and whether this culture hinders or facilitates women's careers in the engineering sector. The findings indicate that many aspects of engineering HE culture are analogous to that which exist in the engineering workplace, although this does not actively deter women from pursuing careers in their chosen profession. However, it is also clear from the research that there are parts of the structural and cultural areas of engineering $\mathrm{HE}$ that women students are not completely satisfied with. The paper suggests that this is because engineering and related courses have been designed for male students. The implication of this is that women do not benefit from an engineering education to the same extent as male students. It is therefore essential that HE engineering reviews it's structure, culture, practices and curriculum if it is not only to retain female engineering graduates, but also to attract more women into the sector.

\section{Acknowledgements}

This research was supported with a grant from the Economic and Social Research Council (ESRC). We are grateful to the universities and particularly the students who took part in the interviews that form the basis of the findings presented in this paper.
Does the Engineering

Culture in UK

Higher Education

Advance Women's

Careers? 


\section{References}

Does the Engineering Bagilhole, B. (2002) Women in Non-Traditional Occupations: Challenging Culture in UK Higher Education Advance Women's Careers? men, Basingstoke: Palgrave Macmillan.

Bagilhole, B. (1997) Equal Opportunities and Social Policy: Issues of gender, race and disability, London: Longman.

Beder, S. (1989) "Towards a more representative engineering education". International Journal of Applied Engineering Education, Vol 5 No 2, pp. 173-182.

Bennett, J.F., Davidson, M.J. and Gale, A.W. (1999) "Women in Construction: A comparative investigation into the expectations and experiences of female and male construction undergraduates and employees", Women in Management Review, Vol 14 No 7, pp. 273-91.

Cockburn, C. (1985) Machinery of Dominance, London: Pluto Press.

Copeland, J. (1995) "Not Stirring Up Trouble: Women engineering students talk", Second Australian Women in Engineering Forum, Melbourne, pp. 13-18.

Dryburgh. H. (1999) "Work Hard, Play Hard: Women and professionalisation in engineering - adapting to the culture", Gender and Society, Vol 13 No 5, pp. 664-82.

Etzkowitz, H., Kemelgor, C. and Uzi, B. (2000) Athena Unbound: The advancement of women in science and technology, Cambridge: Cambridge University Press.

Evetts, J. (1998) "Managing the technology but not the organization: women and career in engineering", Women in Management Review, Vol 13 No 8, p. 283.

Evetts, J. (1997) "Women and careers in engineering: management changes in the work organization", Women in Management Review, Vol 12 No 6, p. 228.

Fielding, J. and Glover, J. (1997) "Gender and Science, Engineering and Technology”, Research Summary, Roehampton Institute, University of Surrey.

Gale, A.W. (1994) "Women in Non-traditional Occupations: The construction industry”, Women in Management Review, Vol 9 No 2, pp. 3-14.

Glover, J., Fielding, J. and Smeaton, D. (1996) "What Happens to Women and Men with SET Degrees?" Labour Market Trends, Vol 104 No 2, pp. 63-7.

Greed, C. (2000) "Women in the Construction Professions: Achieving critical mass", Gender, Work and Organisation, Vol 7 No 3, pp. 181-95. 
Greed, C. (1991) Surveying Sisters: Women in a traditional male profession, London: Routledge.

HESA (2001/2002) “All HE students by subject of study, domicile and gender”, Available: http://www.hesa.ac.uk [Accessed March 2004].

Hodgson, B. (1993) “Opening Science and Technology”, Proceedings of the GASAT 7 International Conference, Ontario, Canada, $31^{\text {st }}$ July- $5^{\text {th }}$ August, 1993.

Jolly, L. (1996) "The first year engineering ethnographic project: An overview", Dept. of Anthropology and Sociology, University of Queensland, Australia.

Jorg, T. and Wubbles, T. (1987) "Physics a problem for girls or girls a problem for physics", International Journal of Science Education Vol 9 No 3, pp. 297-307.

Kanter, R.M. (1977) Men and Women of the Corporation, New York: Basil Books.

Kelly, A. (1985) "The construction of masculine science", British Journal of Sociology of Education Vol 6 No 2, p. 133.

Kirkup, G. and Keller, L.S. (Eds.) (1992) Inventing Women: Science, Technology and Gender, Cambridge: Polity Press.

Lane, N., (1997) "Women in Science, Engineering and Technology: The Rising Tide report and beyond" in: Maynard, M. (Ed.) Science and the Construction of Women, London: UCL Press.

Lewis, S. (1995) "Chilly courses for women? Some engineering and science experiences. Women, culture and universities, A chilly climate? University of Technology, Sydney, Australia.

Lintern, S. (1995) “Oh look ... A girl!” University of South Australia, Mawson Lakes, Australia.

Madhill, H.M., et al. (2003) "Making Choices and Making Transitions Creating A Web Resource", Proceedings of the GASAT 11 International Conference, Mauritius, 6-11 ${ }^{\text {th }}$ July 2003.

McIllwee, J.S. and Robinson, J.G. (1992) "Women in Engineering: gender, power and workplace culture", Albany: State University of New York Press.

McLean, C. et al. (1997) "Masculinity and the culture of engineering”, Australian Journal of Engineering Education, Vol 7 No 2, pp. 143-156.

Mills, J. and Ayre, M. (2003) "Implementing an Inclusive Curriculum for Women in Engineering Education", Journal of Professional Issues in Engineering Education and Practice, Vol 129 No 4, pp. 203-210.

Moxham, S. and Roberts, P. (1995) "Gender in the Engineering Curriculum", University of Melbourne.
Does the Engineering

Culture in UK

Higher Education

Advance Women's

Careers? 
Nair, I. and Majetich, S. (1995) "Physics and engineering in the classroom".

Does the Engineering

Culture in UK

Higher Education

Advance Women's

Careers?
Teaching the majority: Breaking the gender barrier in science, mathematics and engineering in Rosser, S. (Ed.) Teachers College Press, New York, pp. 25-42.

Opportunity 2000, (1996) "Tapping the Talent", Available:

http://www.lboro.ac.uk/orgs/ opp2000/tapping.htm [Accessed 7th May 2004].

Sagebiel, F. (2003) "New Initiatives in Science and Technology and Mathematics Education at the Formal Level: Masculinity cultures in engineering departments in institutions of higher education and perspectives for social change", Proceedings of the GASAT 11 International Conference, Mauritius, 6-11 $1^{\text {th }}$ July 2003.

Srivastava, A.K. (1996) "Widening Access: Women in Construction Higher Education”, PhD Thesis: Leeds Metropolitan University.

Thomas, K. (1990) "Gender and Subject in Higher Education", Buckinghamshire: Open University Press.

Thorn, M. (Ed.) (2000) "Balancing the Equation: Where are the women and girls in science, engineering and technology?" New York: National Council for Research on Women. 